\title{
A New Mathematical Modeling Method for Four-Stage Helicopter Main Gearbox and Dynamic Response Optimization
}

\author{
Yuan Chen $\mathbb{D}^{1,2}$ Rupeng Zhu $\mathbb{D}^{1},{ }^{1}$ Guanghu Jin, ${ }^{1}$ Yeping Xiong, ${ }^{2} \mathrm{Jie}^{\mathrm{Gao}}{ }^{3}$ and Meijun Liao ${ }^{3}$ \\ ${ }^{1}$ College of Mechanical and Electrical Engineering, Nanjing University of Aeronautics and Astronautics, Nanjing 210016, China \\ ${ }^{2}$ Engineering and the Environment, University of Southampton, Boldrewood Innovation Campus, SO16 7QF Southampton, UK \\ ${ }^{3}$ AECC Hunan Aviation Powerplant Research Institute, Zhuzhou 412002, China
}

Correspondence should be addressed to Rupeng Zhu; rpzhu@nuaa.edu.cn

Received 28 June 2018; Accepted 4 September 2018; Published 26 February 2019

Academic Editor: Sing Kiong Nguang

Copyright (C) 2019 Yuan Chen et al. This is an open access article distributed under the Creative Commons Attribution License, which permits unrestricted use, distribution, and reproduction in any medium, provided the original work is properly cited.

A new mathematical modeling method, namely, the finite element method and the lumped mass method (LMM-FEM) mixed modeling, is applied to establish the overall multinode dynamic model of a four-stage helicopter main gearbox. The design of structural parameters of the shaft is the critical link in the four-stage gearbox; it affects the response of multiple input and output branches; however, only the meshing pairs were frequently shown in the dynamic model in previous research. Therefore, each shaft is also treated as a single node and the shaft parameters are coupled into the dynamic equations in this method, which is more accurate for the transmission chain. The differential equations of the system are solved by the Fourier series method, and the dynamic response of each meshing element is calculated. The sensitivity analysis method and parameter optimization method are applied to obtain the key shaft parameters corresponding to each meshing element. The results show that the magnitude of dynamic response in converging meshing pair and tail output pair is higher than that of other meshing pairs, and the wall thickness has great sensitivity to a rotor shaft. In addition, the sensitivity analysis method can be used to select the corresponding shaft node efficiently and choose parameters appropriately for reducing the system response.

\section{Introduction}

The four-stage helicopter main gearbox has three input branches; they converge on the central gear and go one way to the rotor and the other way to the tail chain. The transmission chain includes many parts, which make its structure very complicated. The meshing pairs include internal excitations such as time-varying meshing stiffness and transmission error; in addition, external excitations like torques of the engine, rotor, and tail load also have an important effect on the system. The dynamic response has a profound influence on the fatigue life of the system; therefore, it is necessary to carry out the dynamic analysis for the four-stage helicopter gearbox.

Regarding gearbox modeling, Kubur et al. [1] established the dynamic model of a multishaft helical gear reduction system formed by flexible shafts and studied the influence of some of the key system parameters under forced vibrations. Raclot and Velex [2] simulated the contributions of shape deviations and mounting errors to the dynamic behaviour of multistage geared systems. Choy et al. [3] presented a multistage multimesh gear transmission system; the individual modal component responses and the overall system dynamics of the gearbox were predicted. Dzitkowski and Dymarek [4] obtained the multistage gear mechanical characteristics by properly selecting the dynamical properties of the system based on using the active synthesis method. Chen et al. [5] established the vibration model of a four-stage main transmission system in a helicopter through the lumped mass method, and the influence of the torsional stiffness of shafts on the first five orders of the system's natural frequency was studied. However, in this dynamic model, the shaft was not regarded as a node and all the differential equations are related to the meshing pairs.

In the area of gear response analysis, Parker et al. [6] analyzed the dynamic response of a helicopter planetary gear system under different ranges of operating speeds and torques based on a finite element method and focused on the gear contact conditions. Velex and Flamand [7] calculated 
dynamic tooth loads and response on a planetary gear set by the Ritz method and compared the results with those given by direct integrations for highly reduced computation times. Chaari et al. [8] compared the dynamic response of healthy planetary gears with cracked planetary gears in both the time and frequency domains applied with the Wigner-Ville distribution method. Walha et al. [9] investigated dynamics of a two-stage gear system involving backlash and timedependent mesh stiffness, and the decomposition of a nonlinear system into some linear systems was solved by the Newmark iterative algorithm. Zhou et al. [10] developed a coupled lateral-torsional nonlinear dynamic model with 16 degrees of freedom (16-DOF) of gear-rotor-bearing transmission system considering the nonlinear features, and the mean load excitation had a complicated influence on the coupled system; they concluded that the torsional vibration was the dominant response in the geared system. Chen et al. [11] detected the key shafts of the four-stage helicopter gearbox and analyzed their sensitivity to each branch of the system through the lumped mass method.

Gearbox parameter optimization plays an important role in the helicopter design. Chen and Shao [12] demonstrated the effectiveness of the proposed mesh stiffness model under the influences of the tooth profile modification, not only applied in low contact ratio, but also in high contact ratio. Yang et al. [13] presented the gearbox parameter optimization method by the artificial bee colony algorithm when diagnosing the gear faults and verified the theory through a two-stage parallel shaft gearbox. Bozca [14-16] studied gearbox geometric parameter optimization to reduce rattle noise in an automotive transmission based on a torsional vibration model, and the module, number of teeth, axial clearance, and backlash could be improved through this method. However, system dynamic optimizations were mostly through gear parameters or profile modification; the shaft parameters were not regarded as variables in these researches.

About the sensitivity analysis to system parameters, Lin and Parker [17] and Guo and Parker [18] investigated the natural frequency and vibration mode sensitivities to system parameters. Chen et al. [19] studied the response sensitivity to system parameters like gear mesh stiffness, damping, diameter ratio, and gear mass unbalance in a coupled gear system. However, sensitivity analysis based on multinode dynamic modeling has not been captured by these researches.
In summary, the research of most scholars focuses on the planetary gear chain of the helicopter main gearbox. The dynamic equations also seldom reflect the characteristics of the shaft parameters as independent nodes; thus, it is meaningful to improve the dynamic modeling and propose the optimization method.

\section{LMM-FEM Mixed Modeling}

The dynamic modeling process of a typical four-stage helicopter main gearbox is shown in Figure 1 [20]. Figure 1(a) is the system dynamic model, there are seven meshing elements $(\mathrm{A}, \mathrm{B}, \mathrm{C}, \mathrm{D}, \mathrm{E}$, and $\mathrm{F})$ in the system, and the elements $F$ and $G$ are internal and external meshing pairs in the planetary system, which contains one sun gear, six planet gears, and one carrier. $\theta$ is the rotational degree of freedom (DOF) of each node. Figure 1(b) is a comparison of the LMM modeling method and the LMM-FEM mixed modeling method. In this new method, the gearbox is regarded as finite critical nodes, which include a shaft and a meshing pair; each DOF corresponds to each node of the system. The system's generalized DOF coordinate vector $X$ is

$$
\begin{gathered}
X=\left\{\theta_{1}^{(j)}, \theta_{2}^{(j)}, \theta_{3}^{(j)}, \theta_{4}^{(j)}, \theta_{5}^{(j)}, \theta_{6}^{(j)}, \theta_{7}^{(j)}, \theta_{8}^{(j)}, \theta_{9}, \theta_{10}, \theta_{11}, \theta_{12}, \theta_{13},\right. \\
\left.\theta_{14} \theta_{15}, \theta_{16}, \theta_{17}, \theta_{18}, \theta_{19}, \theta_{20}, \theta_{21}, \theta_{22}, \theta_{23}, \theta_{24}\right\}^{T}
\end{gathered}
$$

2.1. Dynamic Modeling of the Meshing Pairs. For the seven meshing pairs (A, B, C, D, E, F, and G) highlighted in Figure 1 , the time-varying meshing stiffness can be expressed in the Fourier series with meshing frequency $\omega$ [21]:

$$
\left\{\begin{array}{l}
k(t)=k_{m}+k_{a} \sin (\omega t+\beta), \\
k_{s p i}(t)=k_{m, s p i}+k_{a, s p i} \sin \left(\omega t+\beta_{s p i}\right), \\
k_{r p i}(t)=k_{m, r p i}+k_{a, r p i} \sin \left(\omega t+\beta_{r p i}\right),
\end{array}\right.
$$

where $k(t), k_{s p i}(t)$, and $k_{r p i}(t)$ are time-varying meshing stiffness of each gear pair; $k_{m}$ and $k_{a}$ are the average and maximum variable meshing stiffness; $\beta$ is the initial phase of meshing stiffness; and $\omega$ is the fundamental meshing frequency.

The transmission errors are shown in the same way:

$$
\left\{\begin{array}{l}
e(t)=e_{m}+e_{a} \sin (\omega t+\varphi), \\
e_{s p i}(t)=A_{s p i} \sin \left(\omega t+\varphi_{s p i}\right)+E_{p i} \sin \left(\omega_{p H} t+\varphi_{p i}+\alpha\right)+E_{s} \sin \left[\omega_{s H} t+\varphi_{s}-\frac{2 \pi(i-1)}{N}+\alpha\right], \\
e_{r p i}(t)=A_{r p i} \sin \left(\omega t+\varphi_{r p i}\right)+E_{p i} \sin \left(\omega_{p H} t+\varphi_{p i}-\alpha\right)+E_{r} \sin \left[\omega_{r H} t+\varphi_{r}-\frac{2 \pi(i-1)}{N}-\alpha\right],
\end{array}\right.
$$




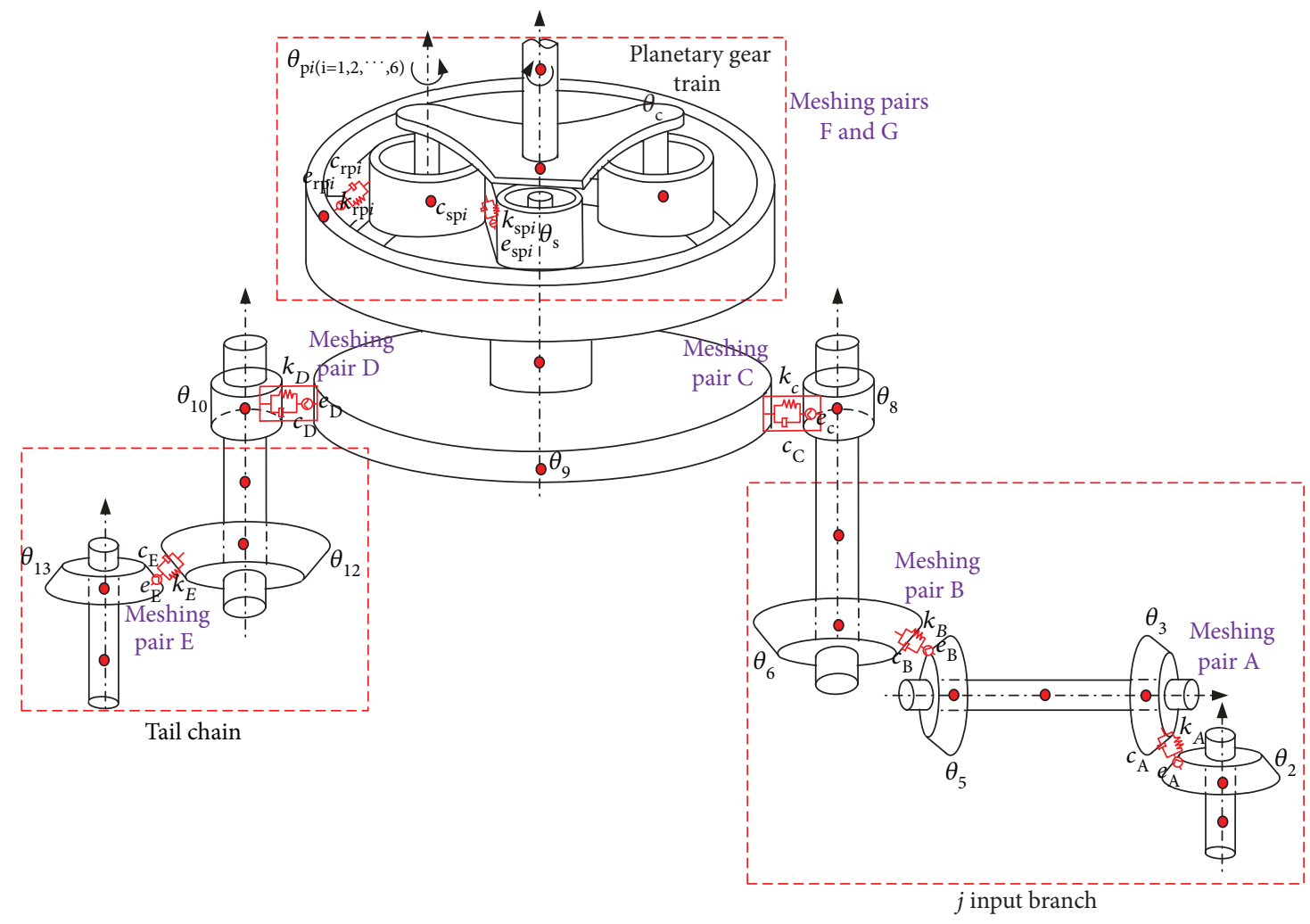

(a) Dynamic model

LMM modeling

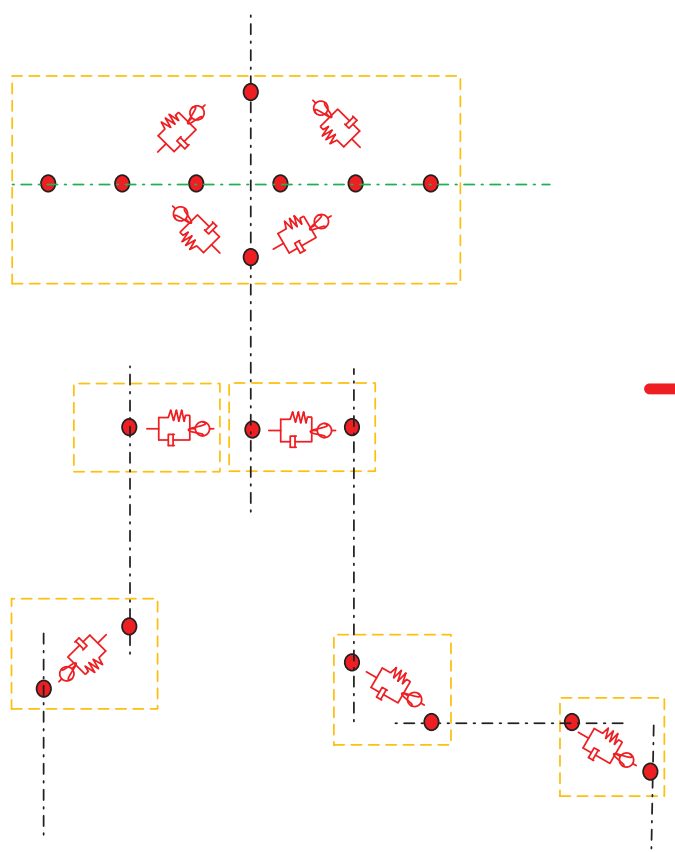

LMM-FEM mixed modeling

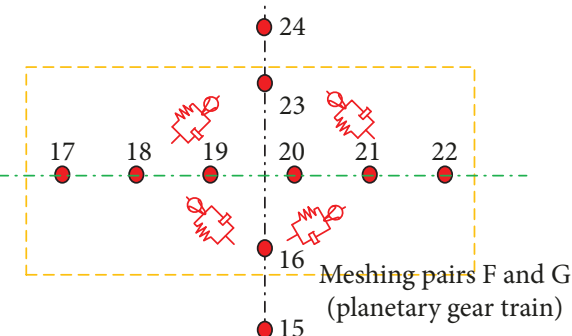

15

Meshing pair D
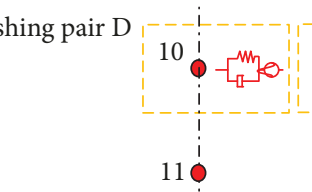

I Meshing pair $\mathrm{C}$

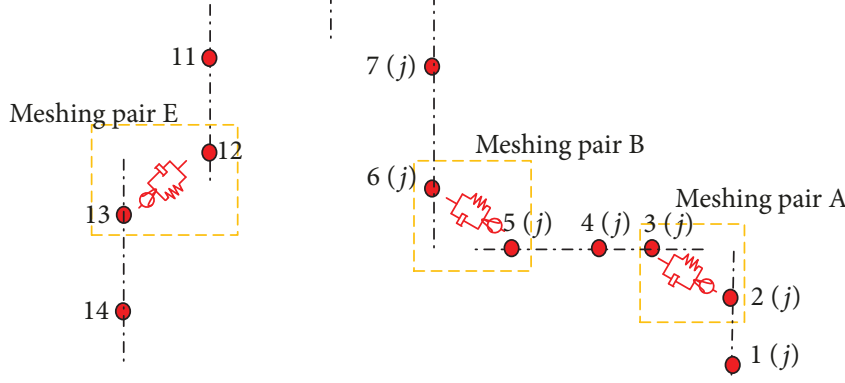

(b) Modeling comparison

Figure 1: Dynamic modeling for the multinode system.

where $e(t), e_{s p i}(t)$, and $e_{r p i}(t)$ are time-varying transmission errors of each gear pair; $e_{m}$ and $e_{a}$ are static and dynamic transmission error amplitude; $\varphi$ is the initial phase of transmission error; $\omega_{p H}, \omega_{s H}$, and $\omega_{r H}$ are rotational frequency of planet gear, sun gear, and carrier; $\alpha$ is the pressure angle; and $N$ is the number of planet gear. 
Tooth deflection along the meshing line is defined as the dynamic response and presented as follows:

$$
X(t)=\theta_{d} r_{d}-\theta_{p} r_{p}-e(t)
$$

where $\theta_{d}$ and $\theta_{p}$ are rotational DOF of drive gear and driven gear and $r_{d}$ and $r_{p}$ are the radii of the base circle in the drive gear and driven gear.

The dynamic forces of each gear pair $F(t)$ are defined as follows:

$$
\left\{\begin{array}{l}
F(t)=F^{p}(t)+F^{d}(t), \\
F^{p}(t)=k(t) X(t), \\
F^{d}(t)=c(t) \dot{X}(t),
\end{array}\right.
$$

where $c(t)$ is the meshing damping and $\dot{X}(t)$ is the relative velocity along the meshing line.

2.2. Differential Equation of Multinode System. According to the dynamic modeling above, the differential equation of the multinode dynamic model can be deduced through Newton's law:

Node 1: shaft node

$$
J_{1} \ddot{\theta}_{1}^{(j)}+G_{1} \frac{\pi D_{1}^{4}}{32 l_{1}}\left(1-\frac{d^{4}}{D^{4}}\right) \theta_{1}^{(j)}=T_{E j}
$$

Nodes 2-3: meshing pair A

$$
\left\{\begin{array}{l}
J_{2} \ddot{\theta}_{2}^{(j)}+\left[F_{2 \_}^{p(j)}(t)+F_{2 \_}^{d(j)}(t)\right] r_{1}+G_{1} \frac{\pi D_{1}^{4}}{32 l_{1}}\left(1-\frac{d^{4}}{D^{4}}\right)\left(\theta_{2}^{(j)}-\theta_{1}^{(j)}\right)=0, \\
J_{3} \ddot{\theta}_{3}^{(j)}-\left[F_{2 \_3}^{p(j)}(t)+F_{2 \_3}^{d(j)}(t)\right] r_{1}+G_{4} \frac{\pi D_{4}^{4}}{32 l_{4}}\left(1-\frac{d_{4}^{4}}{D_{4}^{4}}\right)\left(\theta_{3}^{(j)}-\theta_{4}^{(j)}\right)=0
\end{array}\right.
$$

Node 4: shaft node

$$
\left\{J_{4} \ddot{\theta}_{4}^{(j)}-G_{4} \frac{\pi D_{4}^{4}}{32 l_{4}}\left(1-\frac{d_{4}^{4}}{D_{4}^{4}}\right)\left(\theta_{3}^{(j)}-\theta_{4}^{(j)}\right)+G_{4} \frac{\pi D_{4}^{4}}{32 l_{4}}\left(1-\frac{d_{4}^{4}}{D_{4}^{4}}\right)\left(\theta_{4}^{(j)}-\theta_{5}^{(j)}\right)=0\right.
$$

Nodes 5-6: meshing pair B

$$
\left\{\begin{array}{l}
J_{5} \ddot{\theta}_{5}^{(j)}+\left[F_{5 \_6}^{p(j)}(t)+F_{5 \_6}^{d(j)}(t)\right] r_{5}+G_{4} \frac{\pi D_{4}^{4}}{32 l_{4}}\left(1-\frac{d_{4}^{4}}{D_{4}^{4}}\right)\left(\theta_{5}^{(j)}-\theta_{4}^{(j)}\right)=0, \\
J_{6} \ddot{\theta}_{6}^{(j)}-\left[F_{5 \_6}^{p(j)}(t)+F_{5 \_6}^{d(j)}(t)\right] r_{6}+G_{7} \frac{\pi D_{7}^{4}}{32 l_{7}}\left(1-\frac{d_{7}^{4}}{D_{7}^{4}}\right)\left(\theta_{6}^{(j)}-\theta_{7}^{(j)}\right)=0
\end{array}\right.
$$

Node 7: shaft node

$$
\left\{J_{7} \ddot{\theta}_{7}^{(j)}-G_{7} \frac{\pi D_{7}^{4}}{32 l_{7}}\left(1-\frac{d_{7}^{4}}{D_{7}^{4}}\right)\left(\theta_{6}^{(j)}-\theta_{7}^{(j)}\right)+G_{7} \frac{\pi D_{7}^{4}}{32 l_{7}}\left(1-\frac{d_{7}^{4}}{D_{7}^{4}}\right)\left(\theta_{7}^{(j)}-\theta_{8}^{(j)}\right)=0\right.
$$


Nodes 8-10: meshing pairs C and D

$$
\left\{\begin{array}{l}
J_{8} \ddot{\theta}_{8}^{(j)}+\left[F_{8 \_9}^{p(j)}(t)+F_{8 \_9}^{d(j)}(t)\right] r_{8}+G_{7} \frac{\pi D_{7}^{4}}{32 l_{7}}\left(1-\frac{d_{7}^{4}}{D_{7}^{4}}\right)\left(\theta_{8}^{(j)}-\theta_{7}^{(j)}\right)=0 \\
J_{9} \ddot{\theta}_{9}-\sum_{j=1}^{3}\left[F_{8 \_}^{p(j)}(t)+F_{8 \_9}^{d(j)}(t)\right] r_{9}+G_{15} \frac{\pi D_{15}^{4}}{32 l_{15}}\left(1-\frac{d_{15}^{4}}{D_{15}^{4}}\right)\left(\theta_{9}-\theta_{15}\right)+\left[F_{9 \_10}^{p}(t)+F_{9 \_10}^{d}(t)\right] r_{9}=0 \\
J_{10} \ddot{\theta}_{10}-\left[F_{9 \_10}^{p}(t)+F_{9 \_10}^{d}(t)\right] r_{10}+G_{11} \frac{\pi D_{11}^{4}}{32 l_{11}}\left(1-\frac{d_{11}^{4}}{D_{11}^{4}}\right)\left(\theta_{10}-\theta_{11}\right)=0
\end{array}\right.
$$

Node 11: shaft node

$$
\left\{J_{11} \ddot{\theta}_{11}+G_{11} \frac{\pi D_{11}^{4}}{32 l_{11}}\left(1-\frac{d_{11}^{4}}{D_{11}^{4}}\right)\left(\theta_{11}-\theta_{12}\right)-G_{11} \frac{\pi D_{11}^{4}}{32 l_{11}}\left(1-\frac{d_{11}^{4}}{D_{11}^{4}}\right)\left(\theta_{10}-\theta_{11}\right)=0\right.
$$

Node 12: meshing pair E

$$
\left\{\begin{array}{l}
J_{12} \ddot{\theta}_{12}+\left[F_{12 \_13}^{p}(t)+F_{12 \_13}^{d}(t)\right] r_{12}+G_{11} \frac{\pi D_{11}^{4}}{32 l_{11}}\left(1-\frac{d_{11}^{4}}{D_{11}^{4}}\right)\left(\theta_{12}-\theta_{11}\right)=0, \\
J_{13} \ddot{\theta}_{13}-\left[F_{12 \_13}^{p}(t)+F_{12 \_13}^{d}(t)\right] r_{13}+G_{14} \frac{\pi D_{14}^{4}}{32 l_{14}}\left(1-\frac{d_{14}^{4}}{D_{14}^{4}}\right)\left(\theta_{13}-\theta_{14}\right)=0
\end{array}\right.
$$

Node 14: shaft node

$$
J_{14} \ddot{\theta}_{14}+G_{14} \frac{\pi D_{14}^{4}}{32 l_{14}}\left(1-\frac{d_{14}^{4}}{D_{14}^{4}}\right) \theta_{14}=T_{t}
$$

Node 15: shaft node

$$
\left\{J_{15} \ddot{\theta}_{15}+G_{15} \frac{\pi D_{15}^{4}}{32 l_{15}}\left(1-\frac{d_{15}^{4}}{D_{15}^{4}}\right)\left(\theta_{15}-\theta_{16}\right)-G_{15} \frac{\pi D_{15}^{4}}{32 l_{15}}\left(1-\frac{d_{15}^{4}}{D_{15}^{4}}\right)\left(\theta_{9}-\theta_{15}\right)=0\right.
$$


Nodes 16-23: meshing pairs F and G

$$
\left\{\begin{array}{l}
J_{16} \ddot{\theta}_{16}+\sum_{i=1}^{6}\left[F_{s p i}^{p}(t)+F_{s p i}^{d}(t)\right] r_{16}+G_{15} \frac{\pi D_{15}^{4}}{32 l_{15}}\left(1-\frac{d_{15}^{4}}{D_{15}^{4}}\right)\left(\theta_{16}-\theta_{15}\right)=0, \\
J_{p i} \ddot{\theta}_{p i}-\left[F_{s p i}^{p}(t)+F_{s p i}^{d}(t)\right] r_{p i}+\left[F_{c p i}^{p}(t)+F_{c p i}^{d}(t)\right] r_{p i}=0, \\
J_{23} \ddot{\theta}_{23}-\sum_{i=1}^{6}\left[F_{c p i}^{p}(t)+F_{c p i}^{d}(t)\right] r_{p i}+G_{24} \frac{\pi D_{24}^{4}}{32 l_{24}}\left(1-\frac{d_{24}^{4}}{D_{24}^{4}}\right)\left(\theta_{23}-\theta_{24}\right)=0
\end{array}\right.
$$

Node 24: shaft node

$$
\left\{J_{24} \ddot{\theta}_{24}+\sum_{i=1}^{6}\left[F_{c p i}^{p}(t)+F_{c p i}^{d}(t)\right] r_{p i}+G_{24} \frac{\pi D_{24}^{4}}{32 l_{24}}\left(1-\frac{d_{24}^{4}}{D_{24}^{4}}\right)\left(\theta_{24}-\theta_{23}\right)=-T_{r}\right.
$$

where $T_{E j}$ is denoted as the torque of engine $j(j=1,2,3)$; $D$ and $d$ are the outer and inner diameters of the hollow shaft; $G$ is the shear elastic modulus of the shaft; $T_{t}$ is the output torque of the tail chain; and $T_{r}$ is the output torque of the rotor shaft.

The equations for each DOF could be written as the following matrix-vector form:

$$
[M]\{\ddot{X}\}+[C]\{\dot{X}\}+[K]\{X\}=\{F\}
$$

The excitation $\{F\}$ could be expanded to the Fourier series with the fundamental frequency as well; $k^{\text {th }}$ order excitation is

$$
F_{k}=\left\{A_{1}\right\}_{k} \sin \omega_{k} t+\left\{A_{2}\right\}_{k} \cos \omega_{k} t
$$

The excitation causes the system to generate a response [22]:

$$
\{\Delta x\}_{k}=\left\{B_{1}\right\}_{k} \sin \omega_{k} t+\left\{B_{2}\right\}_{k} \cos \omega_{k} t
$$

where $\left\{B_{1}\right\}_{k}$ and $\left\{B_{2}\right\}_{k}$ could be solved by the following equation:

$$
\left[\begin{array}{cc}
-\omega_{k}^{2}[M]+[\bar{K}] & -\omega_{k}[C] \\
\omega_{k}[C] & -\omega_{k}^{2}[M]+[\bar{K}]
\end{array}\right]\left\{\begin{array}{l}
\left\{B_{1}\right\}_{k} \\
\left\{B_{2}\right\}_{k}
\end{array}\right\}=\left\{\begin{array}{l}
\left\{A_{1}\right\}_{k} \\
\left\{A_{2}\right\}_{k}
\end{array}\right\} .
$$

The dynamic response is the linear superposition of the results corresponded by each order:

$$
\{\Delta x(t)\}=\sum_{k=1}^{5}\left\{\left\{B_{1}\right\}_{k} \sin \omega_{k} t+\left\{B_{2}\right\}_{k} \cos \omega_{k} t\right\}
$$

\section{Numerical Calculation}

3.1. System Parameter and Response Calculation. The parameters of nodes are shown in Table 1 . In addition, the system is powered by three engines, the maximum output power of each engine is $1500 \mathrm{~kW}$, and engine speed is $10,000 \mathrm{rpm}$. The output power of the rotor is $4000 \mathrm{~kW}$, and the rotor speed is $300 \mathrm{rpm}$. The transmission mechanical efficiency is $95 \%$.

The calculation results can be seen from Figure 2, and the dynamic response exhibits periodic vibrations under multifrequency excitation caused by time-varying meshing stiffness and transmission errors; thus, the response amplitudes are different. The gear rotational frequency reduces with the transmission chain following the output branch; in other words, the deceleration effect is obvious.

By comparison, it indicates that the dynamic response of meshing pair E has the maximum amplitude due to the heavy tail output load. In addition, the magnitude of the response in meshing pair $\mathrm{C}$, especially pair $\mathrm{C} 3$, has a relatively higher response as well, as a result of the three-input branches converging at the central gear. Regarding the planetary gear train, the response of planetary gear 1 is greater than that of 


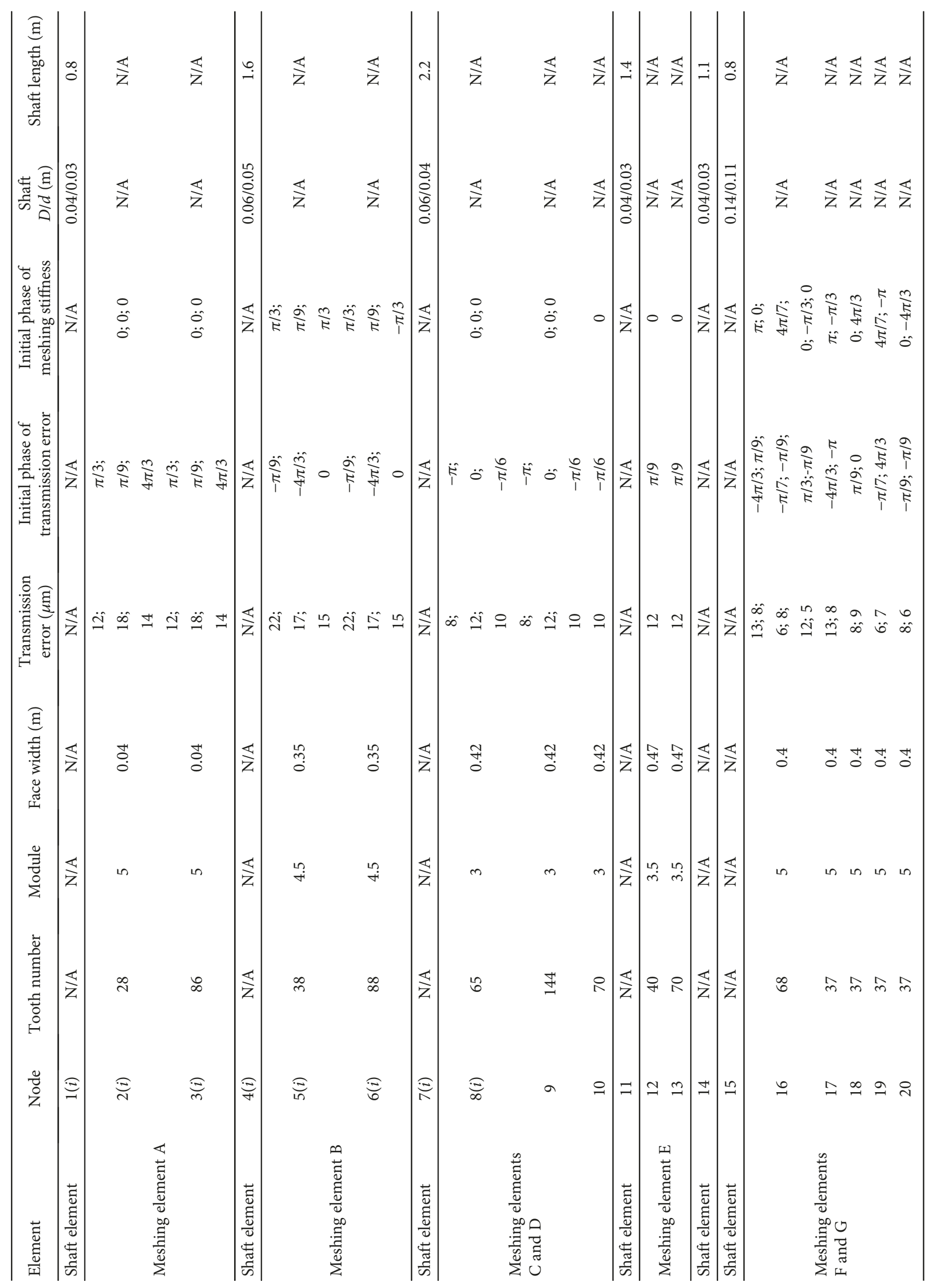




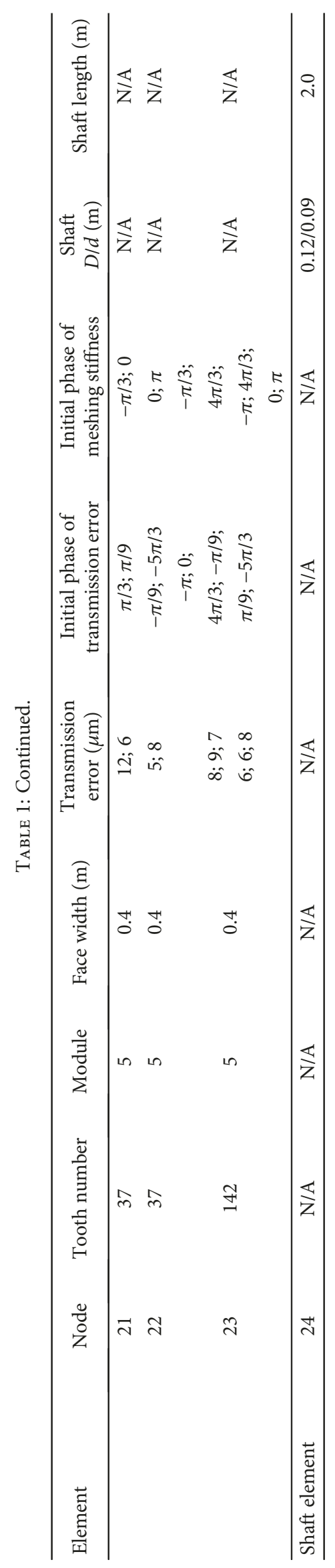




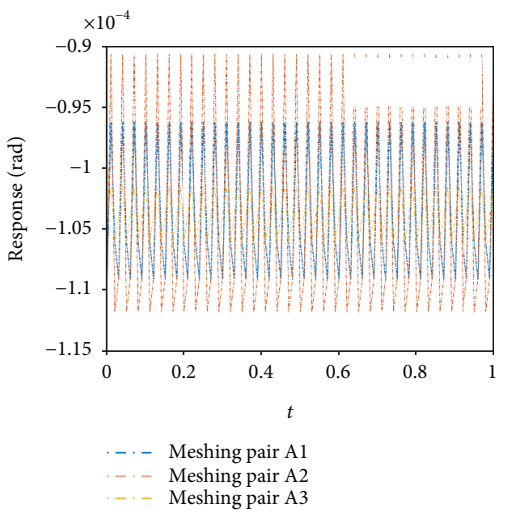

(a) Meshing pair A

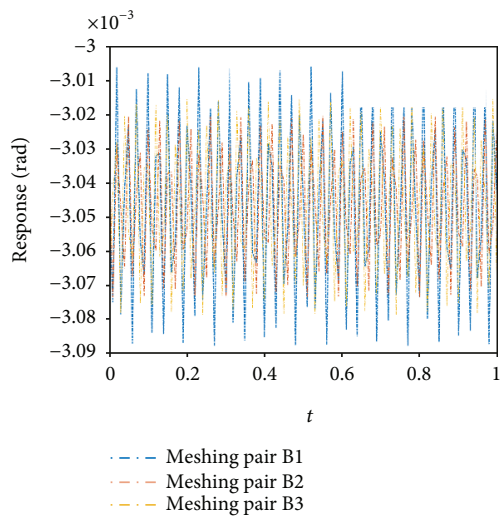

(b) Meshing pair B

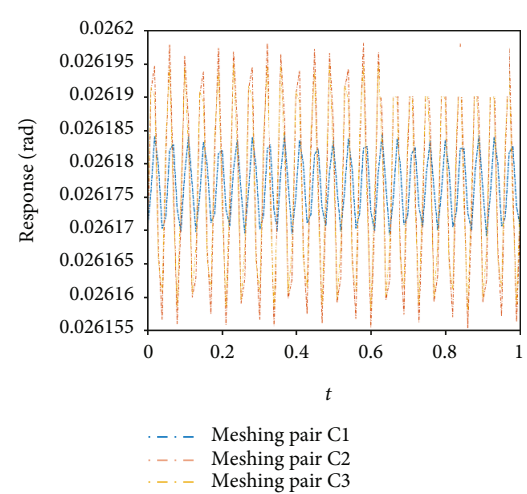

(c) Meshing pair $\mathrm{C}$

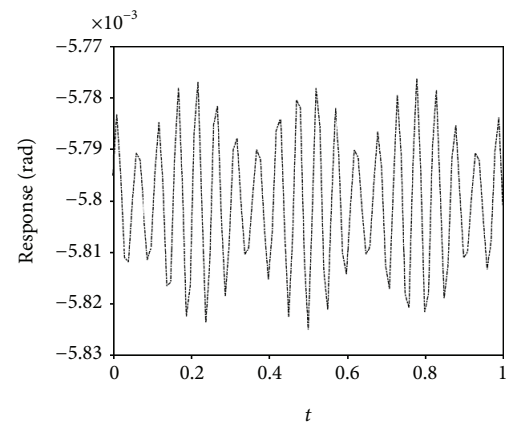

-. - Meshing pair D

(d) Meshing pair D

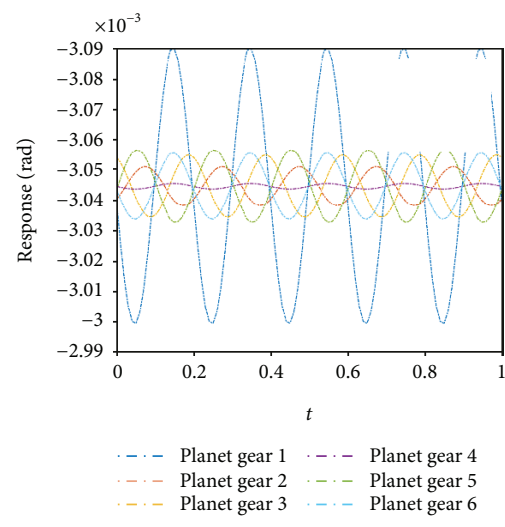

(f) Meshing pair F

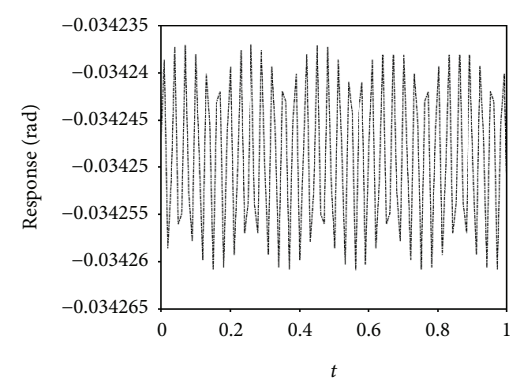

- - - Meshing pair E

(e) Meshing pair E

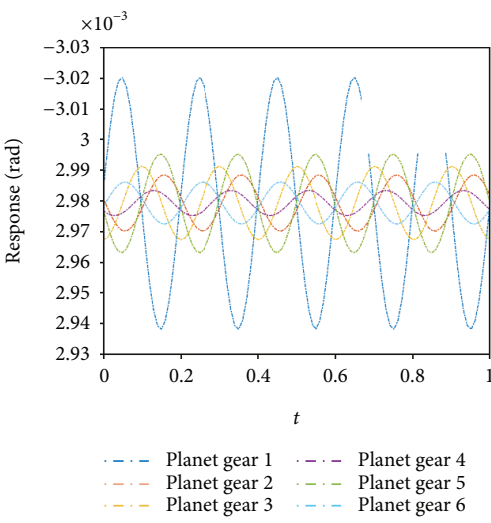

(g) Meshing pair G

Figure 2: Dynamic response regarding tooth deflection in each gear pair.

the other planetary gears due to its largest transmission and manufacturing error.

3.2. Sensitivity Analysis of Responses Influenced by Shaft Wall Thickness. The sensitivity analysis method is widely used to study the key variables under many uncertainties, which can provide a parametric reference for the design of the four-stage helicopter gearbox. In this paper, the ratio of the inner and outer diameters of the shaft is regarded as a variable, the sensitivity coefficient of each pair is calculated, and the key shafts affecting the response characteristics are investigated.
The ratio of the inner and outer diameters of the shaft is defined as $\alpha$; the sensitivity coefficient of the response $x(t)$ to $\alpha$ is defined as follows:

$$
S_{\alpha}^{x}=\frac{\left|\left(x_{\alpha^{\prime}}^{\prime}-x_{\alpha}\right) / x_{\alpha}\right|}{\left|\left(\alpha^{\prime}-\alpha\right) / \alpha\right|} \times 100 \%,
$$

where $x$ and $x^{\prime}$ are the response amplitudes corresponding to the ratio of $\alpha$ and $\alpha^{\prime}$. 


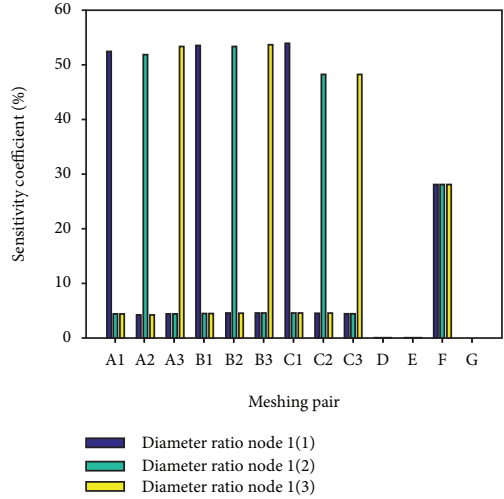

(a) Node 1

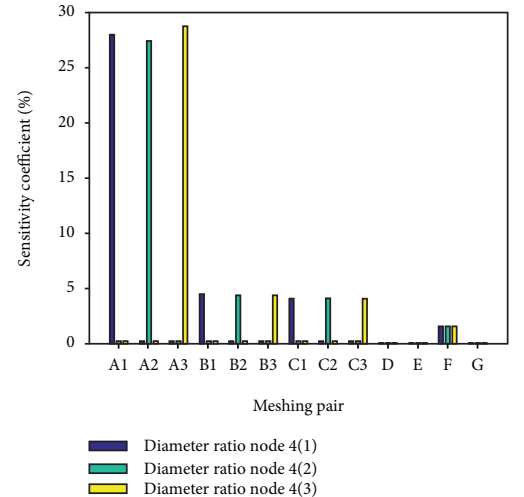

(b) Node 4

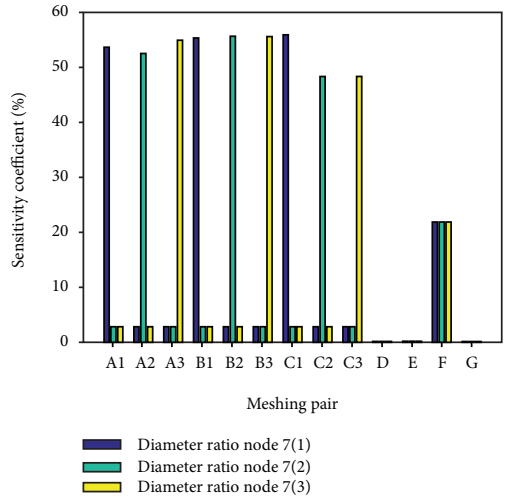

(c) Node 7

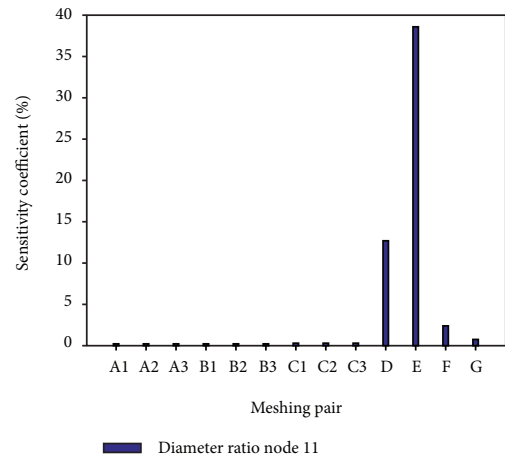

(d) Node 11

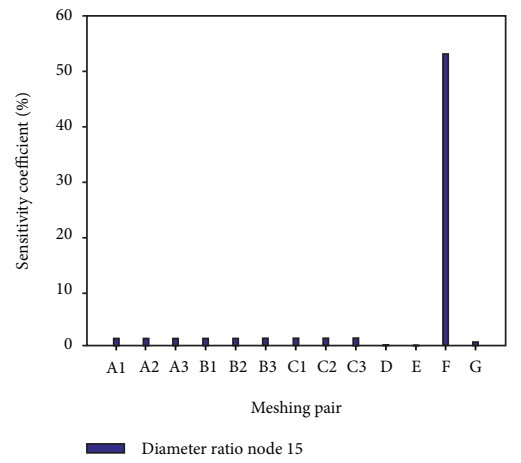

(f) Node 15

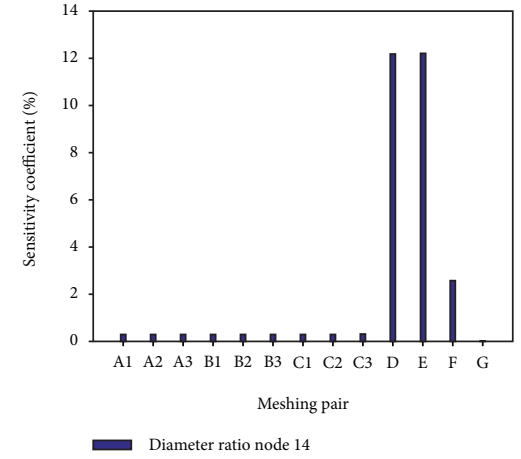

(e) Node 14

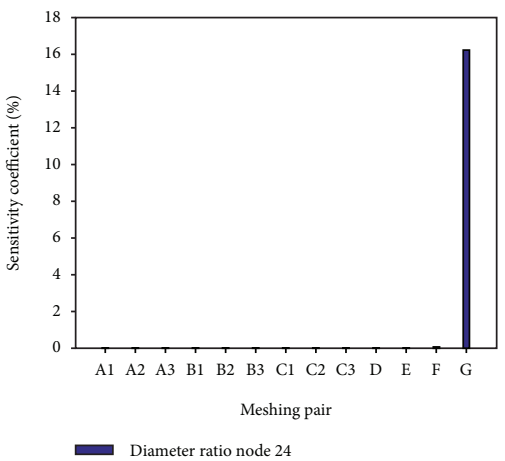

(g) Node 24

Figure 3: Sensitivity coefficient of each meshing pair influenced by $\alpha$.

By changing the diameter ratio $\alpha$, the sensitivity coefficient of each meshing pair is shown in Figure 3. According to Figure 3(a), the sensitivity coefficients of node $1(i)$ to meshing pairs (A, B, and $\mathrm{C}$ ) are greater than $50 \%$, and the coefficient is gradually increased with the transmission chain. Therefore, the diameter ratio of node 1 is the most sensitive to meshing pair C. In addition, node 1 is also about $28 \%$ sensitive to the response of the planetary gear system, and the other meshing pairs are insensitive to this node.

According to Figure 3(b), the sensitivity coefficient of node 4 and meshing pair $\mathrm{A}$ is the highest, which directly affects the dynamic response of the first-stage deceleration, and the sensitivity of the subsequent stages is gradually reduced. The sensitivity of node 7 in Figure 3(c) has the similar influence law as that of node 1 , and the sensitivity coefficients are quite close as well. In Figure 3(d), node 11 has the
TABLE 2: Sensitivity correspondence of wall thickness.

\begin{tabular}{lc}
\hline Meshing pair & Most sensitive node \\
\hline A, B, C & Node 1 and node 7 \\
D & Node 14 \\
E & Node 11 \\
F & Node 15 \\
G & Node 24 \\
\hline
\end{tabular}

highest sensitivity (14.5\% and 38\%) with its adjacent meshing pair D and meshing pair E. In Figure 3(e), node 14 is highly sensitive to the meshing pairs of the tail chain, which includes meshing pairs D and E. In Figure 3(f), the wall 


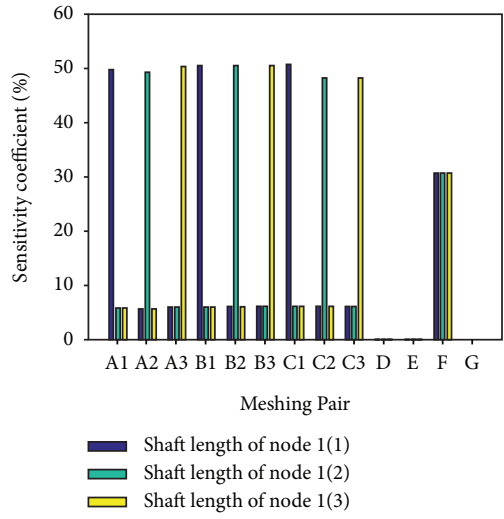

(a) Node 1

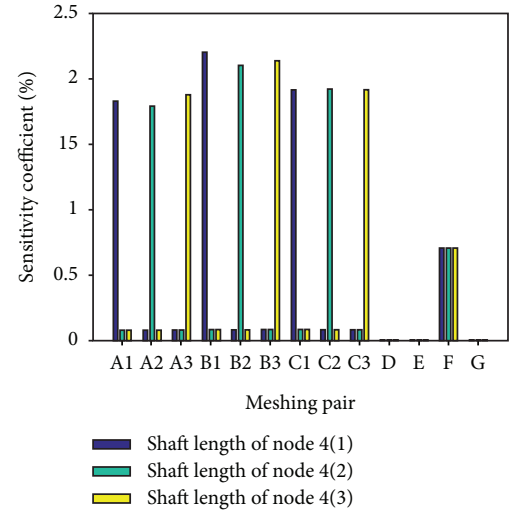

(b) Node 4

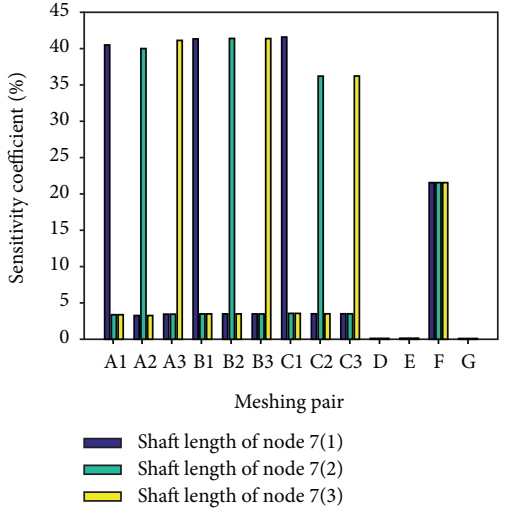

(c) Node 7

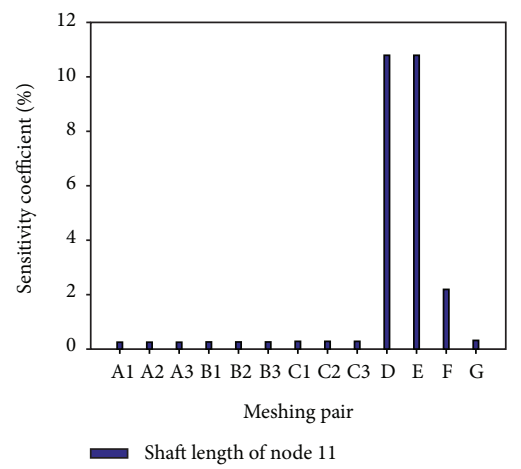

(d) Node 11

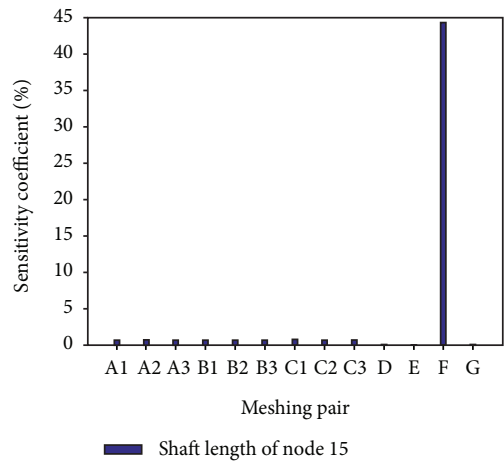

(f) Node 15

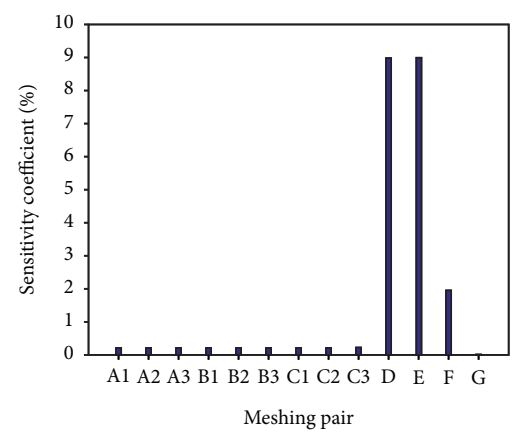

Shaft length of node 14

(e) Node 14

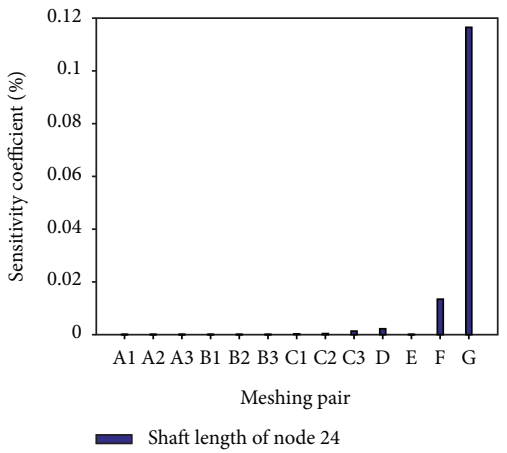

(g) Node 24

FIGURE 4: Sensitivity coefficient of each meshing pair influenced by shaft length.

thickness of node 15, the input shaft of the sun gear, directly affects the response of the planetary gear train; thus, it is the most critical node of meshing pair F. Node 24 in Figure 3(g), the rotor shaft, has the sensitivity of $17 \%$ to meshing pair G, and the coefficient is much larger than that of other nodes.

From these figures, the sensitivity correspondence and shaft selection method regarding wall thickness could be generalized in Table 2, which could be a reference for reducing the vibration shock.

3.3. Sensitivity Analysis of Responses Influenced by Shaft Length. The sensitivity coefficient of the response $x(t)$ to the shaft length is defined as follows [23]:

$$
S_{l}^{x}=\frac{\left|\left(x_{l^{\prime}}^{\prime}-x_{l}\right) / x_{l}\right|}{\left|\left(l^{\prime}-l\right) / l\right|} \times 100 \%,
$$

where $x$ and $x^{\prime}$ are the response amplitudes corresponding to lengths $l$ and $l^{\prime}$.

By changing the only variable parameter shaft length $l$, the sensitivity coefficient of each meshing pair is calculated in the same way, as is shown in Figure 4. From Figures 4(a)-4(c), it can be seen that the three meshing pairs of node 1, node 4, and node 7 have the highest sensitivity to three meshing pairs in the input branch, but the sensitivity coefficient of node 4 is relatively low. In Figures 4(d) and 4(e), node 11 and node 14 
TABLE 3: Sensitivity correspondence of shaft length.

\begin{tabular}{lc}
\hline Meshing pair & Most sensitive node \\
\hline A, B, C & Node 1 \\
D, E & Node 11 \\
F & Node 15 \\
G & None \\
\hline
\end{tabular}

TABle 4: Parameter optimization of the hollow shaft.

\begin{tabular}{lccc}
\hline Parameter & Original group & Improved group & Optimization effect \\
\hline$\alpha_{1}$ & 0.75 & 0.6 & N/A \\
$l_{1}$ & 0.8 & 0.6 & N/A \\
$\alpha_{11}$ & 0.75 & 0.9 & N/A \\
$l_{11}$ & 1.4 & 1.8 & N/A \\
$X_{\mathrm{C} 3}$ & 0.0262 & 0.0171 & $-34.7 \%$ \\
$X_{\mathrm{E}}$ & 0.0343 & 0.0219 & $-36.1 \%$ \\
\hline
\end{tabular}

are similar in the influence law; they both have about $10 \%$ sensitivity coefficient to meshing pairs $\mathrm{D}$ and $\mathrm{E}$. In Figure 4(f), the coefficient of node 15 to meshing pair $\mathrm{F}$ in the planetary gear system is $44 \%$; with the coefficient depicted in Figure 4(f), it could be concluded that the wall thickness and shaft length of node 15 are critical parameters to internal meshing pair in the planetary gear train. In Figure $4(\mathrm{~g})$, although node 24 is the most sensitive to the external meshing pair of the planetary gear system, the sensitivity coefficient is only $0.12 \%$. In addition, the highest response sensitivity correspondence regarding shaft length is generalized in Table 3 .

\subsection{Structural Parameter Optimization Based on Response} Sensitivity Analysis. By the sensitivity analysis of the meshing pairs based on the wall thickness and the shaft length, the most sensitive parameter has been investigated according to Tables 2 and 3. From Figure 2, it could be noted that the maximum response amplitude of the four-stage system is located at meshing pair E, according to the sensitivity analysis; the corresponding node is node 11 . The second largest response amplitude is situated at meshing pair C3, and the corresponding node is node 1 .

Therefore, a parameter optimization method is provided by changing the structural parameters of the shaft node without considering other errors and phase changes. It is initially set that the design range of the shaft diameter ratio $\alpha$ of node 1 is 0.6 to 0.9 , and the range of the shaft length $l$ is 0.6 to $1.4 \mathrm{~m}$. After going through the parameters in the range, the selected diameter ratio and shaft length are shown in Table 4 as an improved group. Similarly, $\alpha_{11}$ is limited to $0.75 \sim 0.9$, and $l_{11}$ is $1.2 \sim 1.8 \mathrm{~m}$; the original group and improved group are selected in the same way. Calculate the dynamic response of the original group and the improved group separately, as shown in Figure 5. From the figure and table, it can be concluded that the response of meshing pair C3 is reduced by $34.7 \%$ and that of meshing pair E

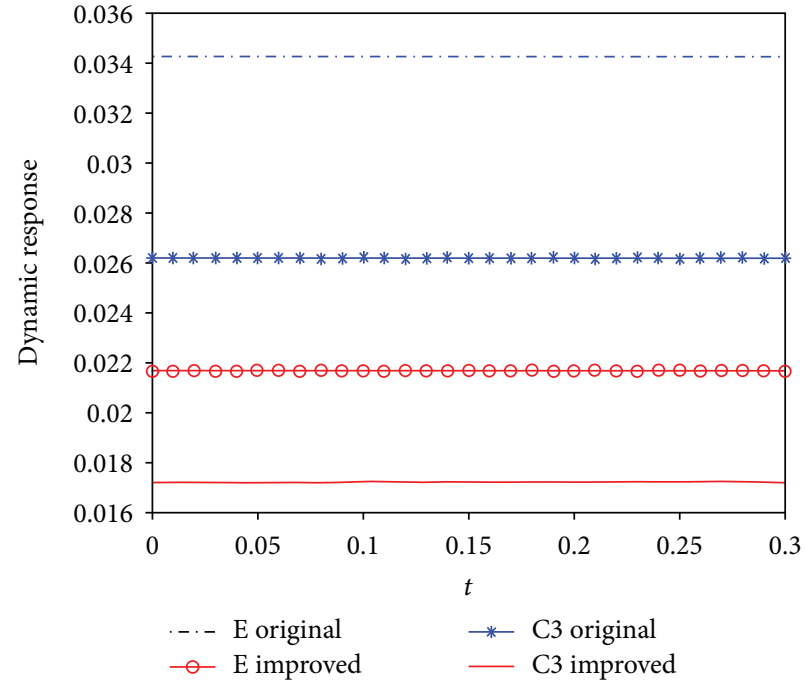

Figure 5: Dynamic response optimization comparison regarding tooth deflection.

is decreased by $36.1 \%$, and the improvement effect is quite obvious.

\section{Conclusion}

Based on the new dynamic modeling method and the response characteristics analysis, the overall multinode dynamic model of a four-stage helicopter main gearbox is established. By solving coupling differential equations, the sensitive laws of wall thickness and length of the hollow shaft are obtained. Therefore, the structural parameter optimization method is proposed to improve the original parameter group. The results enable us to draw the following conclusions:

(1) The magnitude of dynamic response in meshing pairs E and C3 is higher than that of other meshing pairs due to the load torque and converging influence

(2) Each meshing pair has the most sensitive node according to the sensitivity analysis; parameter sensitivity correspondence tables are proposed for the main gearbox design

(3) Regarding the rotor shaft (node 24), the wall thickness has great sensitivity to response; nevertheless, the influence of shaft length is negligible

(4) In the design of the four-stage helicopter main gearbox, the shaft corresponding to node 1 should be relatively short and thick, and the shaft corresponding to node 11 should be comparatively long and thin, which can effectively reduce the response of the system

(5) The sensitivity analysis method can be applied to quickly select the corresponding shaft node and its parameters for reducing the response, which has a good auxiliary effect on system modification. The improvement effect is obvious according to the group comparison 


\section{Data Availability}

The data statement is provided in the supplementary section.

\section{Conflicts of Interest}

The authors declare that there are no conflicts of interest regarding the publication of this paper.

\section{Acknowledgments}

The work described in this paper is fully supported by the National Natural Science Foundation of PRC (Grant no. 51775265), China Scholarship Council, NUAA Short Visiting Program (Grant no. 180403DF05), and Postgraduate Research and Practice Innovation Program of Jiangsu Province (Grant no. KYCX17_0242).

\section{Supplementary Materials}

The uploaded supplementary material is related to the manuscript "A New Mathematical Modeling Method for FourStage Helicopter Main Gearbox and Dynamic Response Optimization." It could validate the authenticity and feasibility of the proposed algorithms. (Supplementary Materials)

\section{References}

[1] M. Kubur, A. Kahraman, D. M. Zini, and K. Kienzle, "Dynamic analysis of a multi-shaft helical gear transmission by finite elements: model and experiment," Journal of Vibration and Acoustics, vol. 126, no. 3, pp. 398-406, 2004.

[2] J. P. Raclot and P. Velex, "Simulation of the dynamic behaviour of single and multi-stage geared systems with shape deviations and mounting errors by using a spectral method," Journal of Sound and Vibration, vol. 220, no. 5, pp. 861-903, 1999.

[3] F. K. Choy, Y. K. Tu, M. Savage, and D. P. Townsend, "Vibration signature and modal analysis of multi-stage gear transmission," Journal of the Franklin Institute, vol. 328, no. 2-3, pp. 281-298, 1991.

[4] T. Dzitkowski and A. Dymarek, "Active reduction of identified machine drive system vibrations in the form of multi-stage gear units," Mechanics, vol. 20, no. 2, 2014.

[5] Y. Chen, R.-p. Zhu, Y.-p. Xiong, and G.-h. Jin, “Analysis on natural characteristics of four-stage main transmission system in three-engine helicopter," Vibroengineering PROCEDIA, vol. 12, pp. 19-23, 2017.

[6] R. G. Parker, V. Agashe, and S. M. Vijayakar, "Dynamic response of a planetary gear system using a finite element/contact mechanics model," Journal of Mechanical Design, vol. 122, no. 3, pp. 304-310, 2000.

[7] P. Velex and L. Flamand, "Dynamic response of planetary trains to mesh parametric excitations," Journal of Mechanical Design, vol. 118, no. 1, pp. 7-14, 1996.

[8] F. Chaari, T. Fakhfakh, and M. Haddar, "Dynamic analysis of a planetary gear failure caused by tooth pitting and cracking," Journal of Failure Analysis and Prevention, vol. 6, no. 2, pp. 73-78, 2006.

[9] L. Walha, T. Fakhfakh, and M. Haddar, "Nonlinear dynamics of a two-stage gear system with mesh stiffness fluctuation, bearing flexibility and backlash," Mechanism and Machine Theory, vol. 44, no. 5, pp. 1058-1069, 2009.

[10] S. Zhou, G. Song, M. Sun, and Z. Ren, "Nonlinear dynamic response analysis on gear-rotor-bearing transmission system," Journal of Vibration and Control, vol. 24, no. 9, pp. 1632-1651, 2018.

[11] Y. Chen, R. Zhu, G. Jin, and Y. Xiong, "Influence of shaft torsional stiffness on dynamic response of four-stage main transmission system," Mathematical Problems in Engineering, vol. 2018, Article ID 6141035, 12 pages, 2018.

[12] Z. Chen and Y. Shao, "Mesh stiffness calculation of a spur gear pair with tooth profile modification and tooth root crack," Mechanism and Machine Theory, vol. 62, pp. 63-74, 2013.

[13] D. Yang, Y. Liu, S. Li, X. Li, and L. Ma, "Gear fault diagnosis based on support vector machine optimized by artificial bee colony algorithm," Mechanism and Machine Theory, vol. 90, pp. 219-229, 2015.

[14] M. Bozca and P. Fietkau, "Empirical model based optimization of gearbox geometric design parameters to reduce rattle noise in an automotive transmission," Mechanism and Machine Theory, vol. 45, no. 11, pp. 1599-1612, 2010.

[15] M. Bozca, "Torsional vibration model based optimization of gearbox geometric design parameters to reduce rattle noise in an automotive transmission," Mechanism and Machine Theory, vol. 45, no. 11, pp. 1583-1598, 2010.

[16] M. Bozca, "Transmission error model-based optimisation of the geometric design parameters of an automotive transmission gearbox to reduce gear-rattle noise," Applied Acoustics, vol. 130, pp. 247-259, 2018.

[17] J. Lin and R. G. Parker, "Sensitivity of planetary gear natural frequencies and vibration modes to model parameters," Journal of Sound and Vibration, vol. 228, no. 1, pp. 109-128, 1999.

[18] Y. Guo and R. G. Parker, "Sensitivity of general compound planetary gear natural frequencies and vibration modes to model parameters," Journal of Vibration and Acoustics, vol. 132, no. 1, pp. 11006-11013, 2010.

[19] C.-S. Chen, S. Natsiavas, and H. D. Nelson, "Coupled lateraltorsional vibration of a gear-pair system supported by a squeeze film damper," Journal of Vibration and Acoustics, vol. 120, no. 4, pp. 860-867, 1998.

[20] Y. Chen, R. P. Zhu, Z. C. Feng, G. H. Jin, and W. Zhang, "Influence of oil film stiffness on natural characteristics of singlerotor three-input helicopter main gearbox," Vibroengineering PROCEDIA, vol. 17, pp. 7-12, 2018.

[21] D.-p. Sheng, R.-p. Zhu, G.-h. Jin, F.-x. Lu, and H.-y. Bao, "Dynamic load sharing characteristics and sun gear radial orbits of double-row planetary gear train," Journal of Central South University, vol. 22, no. 10, pp. 3806-3816, 2015.

[22] M. Li and L. Yu, "Analysis of the coupled lateral torsional vibration of a rotor-bearing system with a misaligned gear coupling," Journal of Sound and Vibration, vol. 243, no. 2, pp. 283-300, 2001.

[23] J. V. Milanović Smieee, C. P. N. Fu, R. Radosavljević, and Z. Lazarević, "Sensitivity of torsional modes and torques to uncertainty in shaft mechanical parameters," Electric Power Components and Systems, vol. 29, no. 10, pp. 867-881, 2001. 


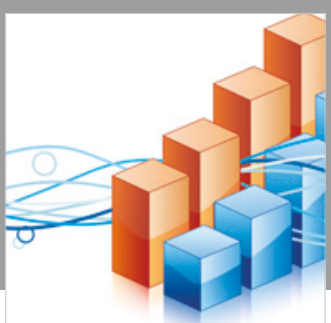

Advances in

Operations Research

\section{-n-m}
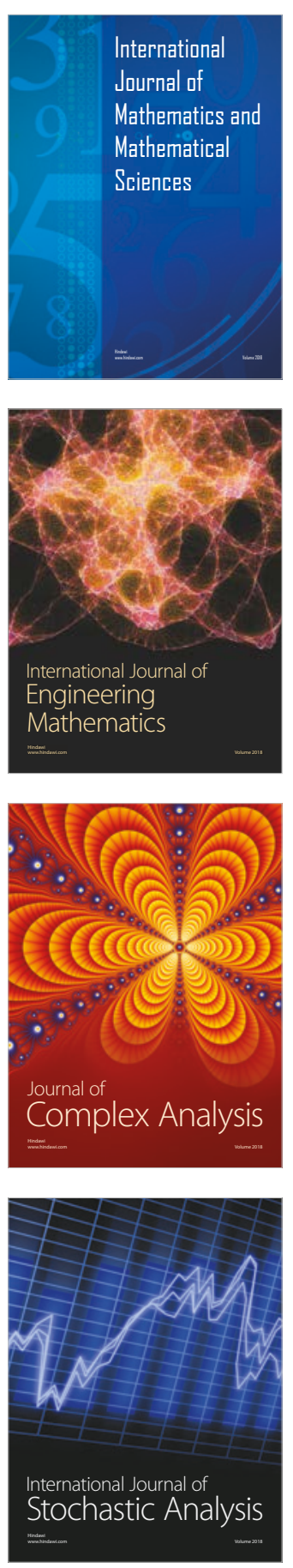
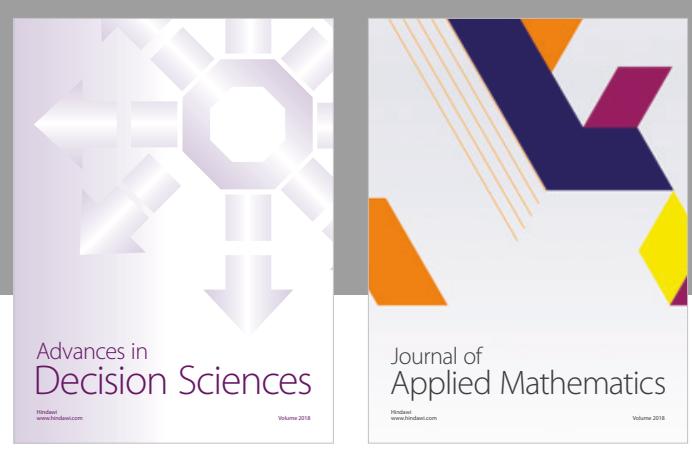

Journal of

Applied Mathematics
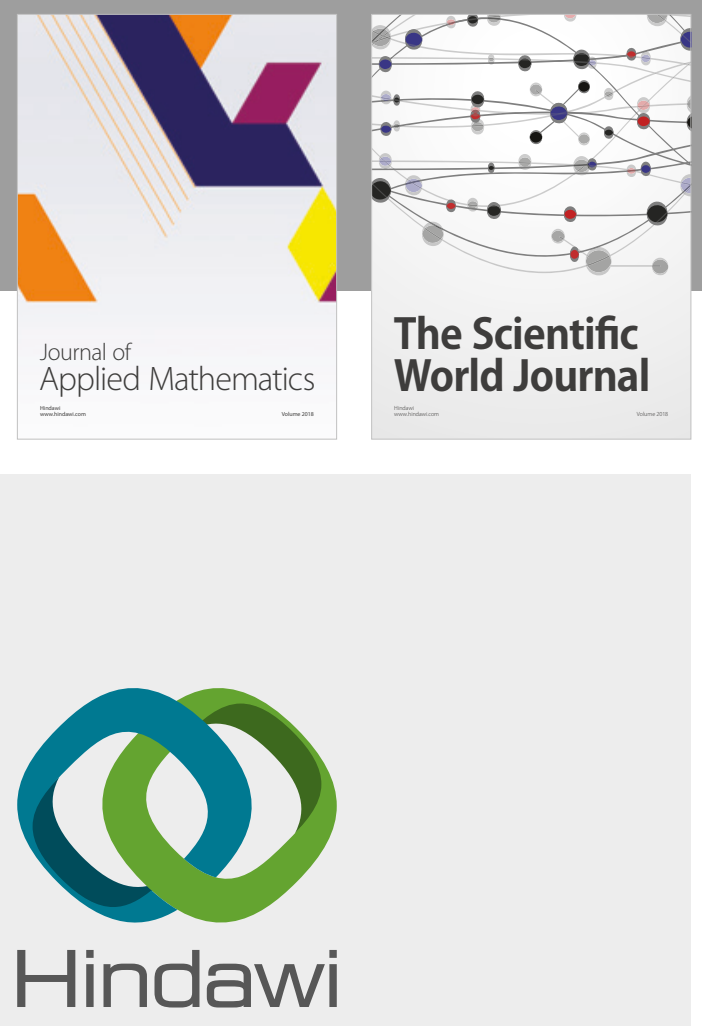

Submit your manuscripts at

www.hindawi.com

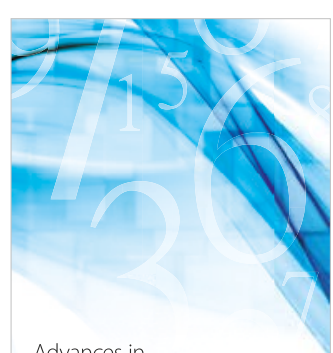

Advances in
Numerical Analysis
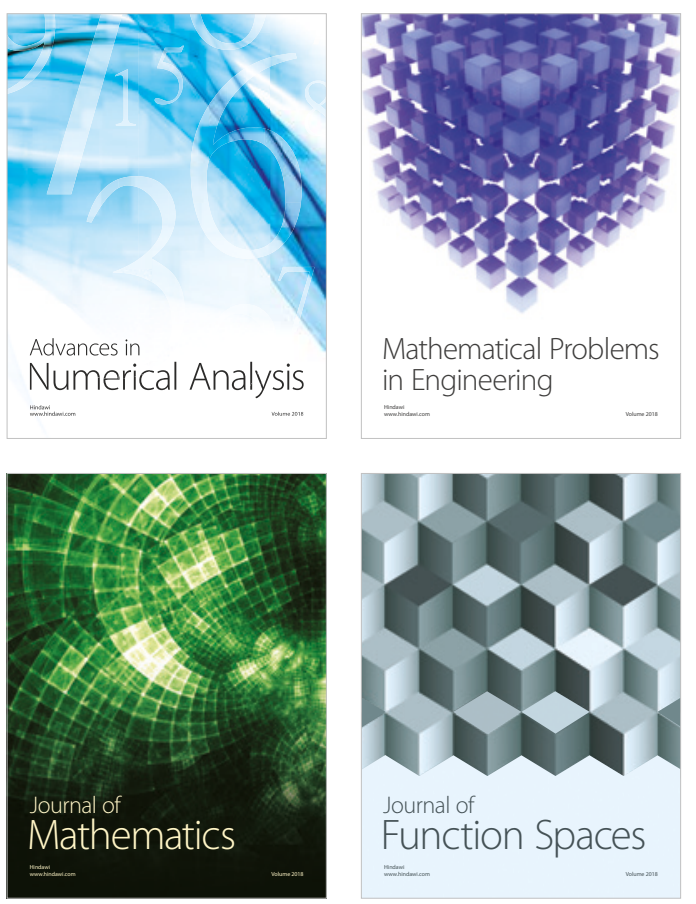

Mathematical Problems in Engineering

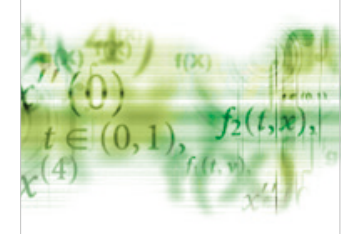

International Journal of

Differential Equations

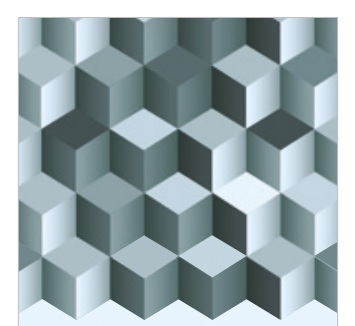

Journal of

Function Spaces
The Scientific

World Journal

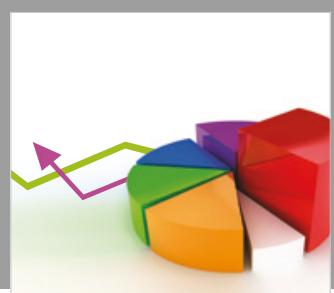

Journal of

Probability and Statistics
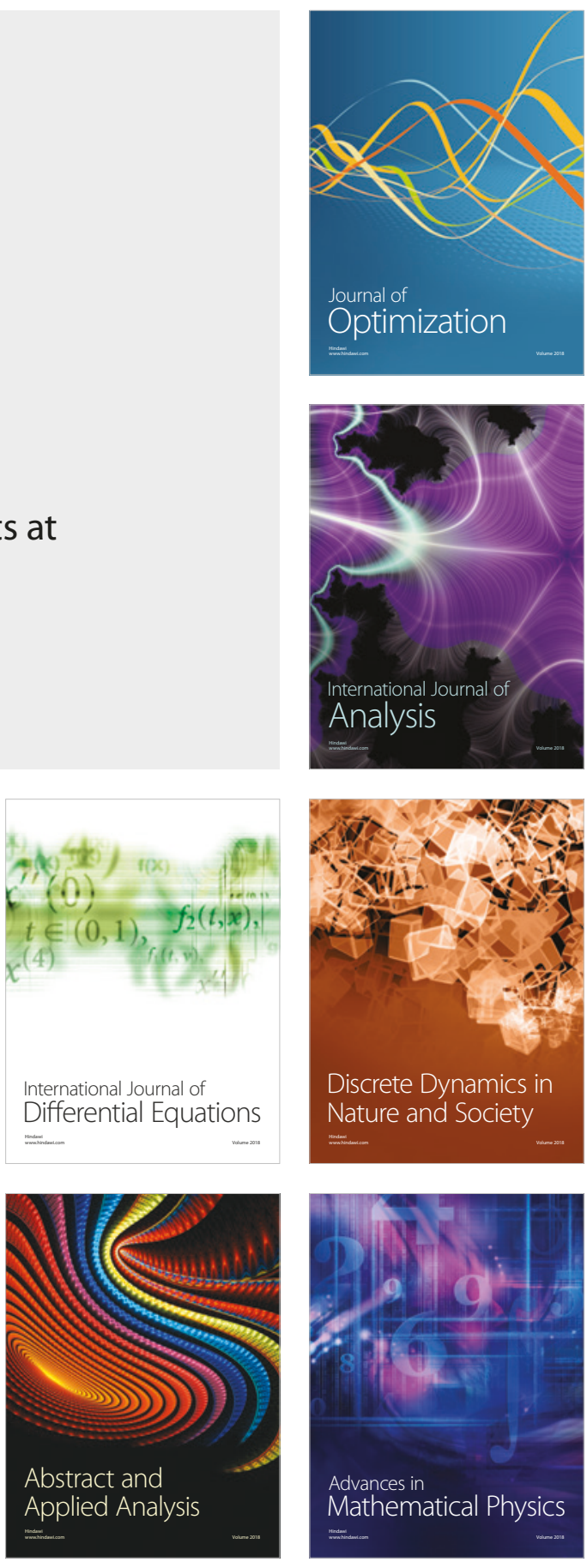